Article

\title{
Moving Forward in Their Journey: Participants' Experience of Taste \& See, A Church-Based Programme to Develop a Healthy Relationship with Food
}

\author{
Riya Patel, Deborah Lycett*, Anne Coufopoulos and Andy Turner \\ Faculty of Health and Life Sciences, Coventry University, Priory Road, Coventry CV1 5FB, UK; \\ patelr34@uni.coventry.ac.uk (R.P.); Anne.Coufopoulos@coventry.ac.uk (A.C.); hsx116@coventry.ac.uk (A.T.) \\ * Correspondence: Deborah.lycett@coventry.ac.uk; Tel.: +44-247-765-5938
}

Academic Editors: Arndt Büssing and René Hefti

Received: 14 November 2016; Accepted: 12 January 2017; Published: 19 January 2017

\begin{abstract}
Quantitative evidence is beginning to document the successful outcomes achieved from holistic interventions that include a spiritual element as an approach to self-manage obesity in the community. However, qualitative research, which helps us understand the reasons behind their success, is scarce. Our aim was to explore participants' acceptance of and engagement with the Taste \& See programme. Semi-structured interviews were carried out after participants had completed the Taste \& See programme. Interviews were transcribed and analysed using deductive thematic analysis. Themes showing that 'God and food issues had been kept separate' at the start of the programme and that participants then 'Began to use faith as a resource' were identified. Also, while 'Eating freely was a challenge' initially, participants later found 'empowerment and enjoyment in freedom'. 'Addressing more than just a weight problem' was valued highly and there were benefits and difficulties that arose from 'Coping with other group members'. The rich level of evaluation provided through this study identifies that the participants found the programme a novel experience. The intervention was acceptable and participants engaged well with the programme content.
\end{abstract}

Keywords: obesity; weight; religion; spirituality; church-based; faith-based; Christian; intervention; feasibility trial; qualitative; acceptability; UK; engagement

\section{Background}

Obesity treatment is a high priority globally [1]. Evidence from cross-sectional studies indicates that religion and spirituality are positively associated with a better diet, which includes higher consumption of fruit and vegetables [2,3], higher fish intake [4] and lowered fat intake amongst specific Christian denominations (e.g., Seventh-Day Adventists) [3]. Systematic review evidence [5] is beginning to document the successful outcomes achieved from holistic interventions that include a spiritual element as an approach to self-manage obesity in the community. However, qualitative evidence that seeks to develop an understanding of why a spiritual element is important to participants in these programmes is limited [6]. According to the Medical Research Council (MRC) guidelines for the evaluation of complex interventions, an important part of an evaluation process is a qualitative exploration of the intervention. This can provide valuable insight into the successful and unsuccessful mechanisms of an intervention, as well as providing evidence of any unexpected outcomes that are not always easily disclosed using quantitative measures [7]. 


\section{Aim}

To explore participants' experience of participating in Taste \& See, a Christian, church-based, healthy, intuitive eating, weight management programme in the United Kingdom.

\section{Objectives}

- To explore how participants engage with the programme, content and materials.

- $\quad$ To explore how acceptable participants find the programme.

\section{Methods}

This qualitative study was carried out as part of the Taste \& See feasibility study, the protocol [8] and main results [9] of which are published elsewhere. Ethical approval was provided by Coventry University Research Ethics Committee. The paper is reported in accordance with the Consolidated Criteria for Reporting Qualitative Research [10].

\subsection{Participants}

Participants were recruited purposively, where all those who had taken part in the feasibility trial of the Taste \& See programme were invited to participate in an interview. A total of 15 out of the 18 participants took part in semi-structured interviews post-intervention during July-August 2015. Three participants could not participate in interviews due to the time commitment involved. The interviews typically lasted between 30-40 min.

\subsection{Data Collection}

Before the trial began, an information session was held where participants were given the opportunity to ask what their participation would involve. They were given participant information sheets to take away and read. The following week participants were screened for eligibility to take part and invited to give consent to participate. During the final session of the programme, participants were reminded about the post-intervention interview. Interview schedules were given to participants ahead of the interview, so they could read and make notes around the schedule. The semi-structured interview schedule (Table 1) was designed and used as an aide-memoire during the interviews.

Table 1. Semi-structured interview schedule.

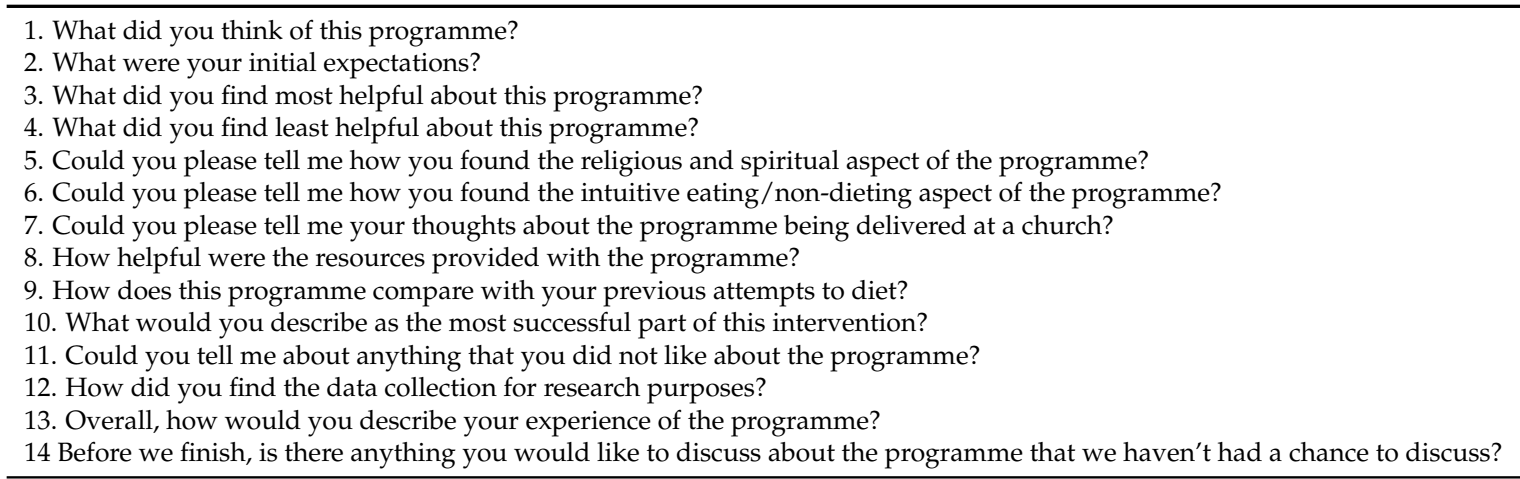

The majority of the interviews were conducted face-to-face; one participant did not want to participate in a face-to-face interview and chose to provide their feedback about the programme via e-mail. Riya Patel conducted the interviews under the supervision of Deborah Lycett; the interviews were carried out at the church where the intervention was delivered. Only the interviewers and participant were present during the interviews. 
In line with realist research practice [11,12], during the interview the researcher summarised the key points covered to establish whether she had correctly interpreted the participant, this allowed participants to revise or clarify their views. Participants were also offered a chance to add to their answers at any point, and were provided an opportunity again at the end of their interviews. Transcripts were not returned to participants for checking and they were not asked to provide feedback on the results. This was because we wanted to explore how participants felt about the programme as soon after completing it as possible. With further time to reflect, these feelings may have changed; in particular, strong feelings important to the acceptance of the programme may have been diluted.

\subsection{Data Analysis}

All the interviews were audio-recorded and transcribed verbatim for analysis by Riya Patel. Transcripts were analysed using thematic analysis, as outlined by Braune and Clarke [13]. Each transcript was analysed separately and coded deductively at a semantic level. The researcher adopted a realist approach wherein the participant's experiences were taken at face value, as it was assumed that they were reporting the truth about their experiences of participating in the programme. Transcripts were read and re-read, and line-by-line coding was completed. Nvivo 10 (Qualitative Solutions and Research International, Doncaster, Victoria, Australia) data management software was used to organize and manage the data. The coding process progressed by moving back and forth across the dataset in an iterative process where comparisons were made between codes and phrases. Those with similar context or concepts were grouped together. Peer review was also performed by two of the co-authors (Deborah Lycett and Andy Turner), who agreed with the themes that were developed. Riya Patel also had frequent discussions with Deborah Lycett to ensure that the data interpretation was credible, valid and shared.

\subsection{Reflexivity}

Riya Patel is a Ph.D. student with a background in health psychology; this study was conducted as a part of her Ph.D. Riya Patel had established professional relationships with the participants through facilitating during the intervention and trial data collection.

Riya Patel identifies herself as an insider to the phenomena under focus, as she is a British Indian woman who belongs to the Christian faith and actively practices her faith by attending church weekly. She also has a personal, as well as academic, understanding of the weight-related issues (e.g., psychological issues like stigma, as well as eating for reasons like boredom) that participants discussed.

There are benefits to being an insider in qualitative research: an insider can share and identify with the experiences of participants, is equipped with insights into the phenomena, and possesses the ability to understand implied content [14]. With this in mind, issues with being an insider also arise, which include the risk of blurring boundaries due to the familiarised understanding that derives from the 'insider' researcher, imposing one's own beliefs through directing the interview and direction of participant's discussion, and over-disclosure of one's own experiences, which might shift the focus of the interview away from the participant [15].

To counter this, these issues were considered in the beginning prior to the research, and subsequent measures, such as journaling with engagement in deep reflexivity, plus continuously asking for clarification of participants' accounts, were taken to ensure the voice of the participant was not lost or misinterpreted. In particular, the researcher reflected on her role during the interviews and made changes in her approach, the questions asked and the manner they were phrased so that a clearer participant voice was heard in subsequent interviews.

Particular care was taken during the coding and analysis of data so that the deductive coding was completed in line with the clear aims of the study, rather than directed by researcher influence. The researcher refrained from insinuating meaning based on what the participants had said. A clear 
audit trail was created with annotations that highlighted the thought processes the researcher had when collating the codes into sub-themes and then themes.

\section{Results}

Of the 15 participants who took part in the interviews, the majority were females belonging to the Christian faith. The demographics of the participants are presented in Table 2.

Table 2. Participants' demographics.

\begin{tabular}{|c|c|c|c|c|c|}
\hline & & \multicolumn{2}{|c|}{ Interviewees } & \multicolumn{2}{|c|}{ Those Not Interviewed } \\
\hline \multicolumn{2}{|c|}{ Participant Characteristics } & Mean & SD & Mean & SD \\
\hline \multirow[t]{2}{*}{ Age (Years) } & & 48.1 & 13.8 & 43.3 & 21.8 \\
\hline & & \multicolumn{2}{|c|}{ N (\% Frequency) } & \multicolumn{2}{|c|}{ N (\% Frequency) } \\
\hline \multirow{2}{*}{ Sex: } & Male & \multicolumn{2}{|c|}{$2(13)$} & \multicolumn{2}{|c|}{$1(33)$} \\
\hline & Female & \multicolumn{2}{|c|}{$13(87)$} & \multicolumn{2}{|c|}{$2(67)$} \\
\hline \multirow{3}{*}{ Ethnicity: } & White & \multicolumn{2}{|c|}{$13(87)$} & \multicolumn{2}{|c|}{$3(100)$} \\
\hline & Black & \multicolumn{2}{|c|}{$1(6.5)$} & \multicolumn{2}{|c|}{$0(0)$} \\
\hline & Asian & \multicolumn{2}{|c|}{$1(6.5)$} & \multicolumn{2}{|c|}{$0(0)$} \\
\hline \multirow{3}{*}{ Religion: } & Christian & \multicolumn{2}{|c|}{$13(87)$} & \multicolumn{2}{|c|}{$3(100)$} \\
\hline & Sikh & \multicolumn{2}{|c|}{$1(6.5)$} & \multicolumn{2}{|c|}{$0(0)$} \\
\hline & Spiritual, but not religious & \multicolumn{2}{|c|}{$1(6.5)$} & \multicolumn{2}{|c|}{$0(0)$} \\
\hline \multirow{4}{*}{ BMI category: } & Healthy (with high TFEQ) & \multicolumn{2}{|c|}{$3(20)$} & \multicolumn{2}{|c|}{$0(0)$} \\
\hline & Overweight & \multicolumn{2}{|c|}{$3(20)$} & \multicolumn{2}{|c|}{$1(33)$} \\
\hline & Obese & \multicolumn{2}{|c|}{$6(40)$} & \multicolumn{2}{|c|}{$2(67)$} \\
\hline & Morbidly Obese & \multicolumn{2}{|c|}{$3(20)$} & \multicolumn{2}{|c|}{$0(0)$} \\
\hline
\end{tabular}

Following close engagement with the data, seven super-ordinate themes were identified: 'God and food issues had been kept separate', 'Beginning to use faith as a resource', 'Eating freely was a challenge', 'There is empowerment and enjoyment in freedom', 'Addressing more than just a weight problem', 'Coping with other group members', and 'Journeying towards a healthier relationship with food'. All super-ordinate themes encapsulated sub-themes, all of which are illustrated with a series of extracts.

\section{Theme 1: God and food issues had been kept separate}

The spiritual component of this weight loss programme was a novel and salient experience for participants. The theme 'God and food issues were separate' illustrates the initial stages of participants' engagement with the spiritual component of the intervention. This theme captures participants' initial thoughts and feelings about where God and their spirituality fit within their eating behaviour. The data for this theme has been organised into three sub-themes, which are now explored in more detail.

\section{Subtheme 1: Food issues had never been taken to God before}

Participants described how their faith was central to their lives; most of the participants actively engaged with their faith daily. At the start of the course, the idea of spirituality in relation to eating was a new concept that needed to be worked through as bringing God into their eating was not something they had previously considered.

"When it comes to ... eating healthy and all of that, no, I'd never attached that [to] God" 
Subtheme 2: Food issues were considered too trivial for God

When participants started to consider the role that God played in their food-related struggles, many participants believed that the issues they experienced were too trivial for God to be interested in. Participants identified how they felt their eating behaviour was something they had to deal with by themselves, illustrating a reason why issues associated with food were not previously taken to God.

"At the beginning I did find it difficult ... I felt it was trivial for God ... taking things about eating and dieting and weight to Him."

[Extract 2, Participant 2]

"Previously I would have thought [issues related to weight] are just too trivial for God to be bothered about, [and] actually it was my responsibility to sort them out."

[Extract 3, Participant 3]

\section{Subtheme 3: Shame prevented participants from bringing God into their eating}

For many participants, the issues they had with food and the problems they faced represented great failures in their lives, whereas their relationship with God was viewed positively. Accounts from the participants suggested that feelings of guilt and shame meant they deliberately kept God separate from their eating behaviour.

"I never brought them together because as far as I'm concerned my eating is a big, well, a failed area of my life; whereas my faith and my relationship with God has just gone from strength to strength. I always speak to God about how I'm feeling emotionally and pray for help and support with all other areas; it [my eating] is one of those areas that I've kept very separate."

[Extract 4, Participant 4]

Some participants felt that the problems they have with food and eating should be something they attempt to deal with themselves first before they take it to God, which further illustrates shame and therefore a deliberate attempt to keep this issue away from God.

"I've always had the mind-set I'll take it to God, I'll pray about it, but I have to lose weight first."

[Extract 5, Participant 5]

\section{Theme 2: Beginning to use faith as a resource}

The theme 'beginning to use faith as a resource' encompasses the next part of the participants' journey and begins to show how participants engaged with the spiritual element as they progressed through the course; this has been captured through four sub-themes.

\section{Subtheme 1: Realising God does want to help}

From having never relinquished their weight-related struggles to God, participants transitioned to a place where they realised that God does want to help them with their weight-related struggles.

I ... found the fact that God does want to help me in this [overcoming emotional eating] helpful, because ... it [was] something which I thought was trivial, really not something necessarily that God would be interested in."

[Extract 6, Participant 2]

This acknowledgement meant that participants started to ask God for help with their food issues. 
Subtheme 2: Drawing on faith to achieve a healthier relationship with food

As participants started to understand that God wanted to help them in this area, participants began drawing on their faith and applying their faith in different ways to their eating.

Some of the participants identified how they were not just praying for weight loss, rather they were praying specifically about certain areas they wanted help with in relation to their issues with weight, and noted how they were drawing on strength from God to help them.

“But obviously, it was not simple as just praying and it happens. Now I realise it's praying for the strength to be able to do [and] fulfil what it [is] that I actually want to happen; so I need the strength to be able to ... make sure I ... exercise regularly [and] make sure I'm content with [the] food I'm eating."

[Extract 7, Participant 6]

Some participants noted how perceiving their relationship with food through the lens of their faith meant they were reading and applying Bible verses in a whole new context. Interpreting their eating behaviours through what Bible scriptures teach led participants to be more mindful about their motives behind eating.

“God's given us a brain and it's for understanding His word. Overindulgence, selfishness, greed, gluttony, those are things I didn't actually think about when you grew up and have at sort of meals."

[Extract 8, Participant 7]

“'Everything is permissible but not everything is beneficial' that's given me ... a clearer understanding of how I can stop, think, before I act, consider it, reflect on things, then go do it."

[Extract 9, Participant 7]

\section{Subtheme 3: God's love as a catalyst for self-love}

The content of the programme that considered God's love and acceptance led participants on a journey towards self-love and self-care. The quotes below demonstrate that as participants began to see and love themselves the way God sees and loves them, they experienced a change in their motivation to manage their food and weight.

"This experience has taught me how to love myself, the love God has for me, and how precious my body is in all aspects—inside and out—so what I put in it is really important."

[Extract 10, Participant 1]

"God loves me as I am but wants me to love myself and lose some weight to be healthy"

[Extract 11, Participant 2]

\section{Subtheme 4: No discomfort with, and applicability of, Christian spirituality}

Some participants described that despite not belonging to the Christian faith, the Christian spirituality discussed on the programme did not isolate them or pose as a barrier preventing them from participating. Participants reported that they were comfortable with this element and it was not forced on them.

“I didn't feel pressured, no, I could take it or leave it. If I didn't want to pray-I didn't pray."

[Extract 12, Participant 8] 
'I mean I felt even though I'm a non-Christian it was still ... very applicable...there [was] very general well-being, good stuff ... I didn't find that a barrier at all."

[Extract 13, Participant 6]

Participants felt that that they could identify with Christian spirituality despite not belonging to the Christian faith group and they could still apply and relate the messages of this element to their eating behaviours.

"A lot the Bible readings were common sense, I mean there were a couple of times when I thought ... I'm not sure of that one, but I don't think I was the only person, you know, and sometimes we thought, well, actually, no [I] don't really relate to that, and other times you just think, well, actually, you know, that's common sense whether you believe it comes from a God or a universe or whatever-for me it still makes sense."

[Extract 14, Participant 8]

\section{Theme 3: Eating freely was a challenge}

Freedom from dietary restrictions formed another novel aspect of Taste \& See. The theme 'eating freely was a challenge' explores participants' initial encounter with the 'unconditional permission to eat' element of intuitive eating. The data for this theme was captured using the three sub-themes presented below.

\section{Subtheme 1: Freedom felt dangerous}

When participants described their early thoughts about the freedom component of the intervention, participants used phrases like "Playing with fire" and "a license to indulge" and described how freedom felt like a temptation to eat everything, which seemed counterintuitive to their reasons for joining the programme.

"It was really almost like opening the floodgates and saying right, okay, you can have everything; go and empty Tesco's."

[Extract 15, Participant 8]

\section{Subtheme 2: Freedom felt too good to be true}

For many participants, their initial thoughts about the dietary freedom of the programme raised scepticism, as it was going against their existing beliefs about how to lose weight.

"Initially I was a bit sceptical, because it just seems like one of those diets that you see in the Daily Mail, like 'oh eat what you want and still lose 5 stone'... . It just seemed a bit too good to be true."

[Extract 16, Participant 6]

"'Cos to me, losing weight is deprivation of something; you know, I didn't really see to begin with how you could not do that and lose weight."

[Extract 17, Participant 5]

\section{Subtheme 3: Freedom gave rise to feelings of uncertainty about the programme's success}

Whilst practicing intuitive eating, some of the interviews suggested that freedom gave rise to feelings of uncertainty about successful weight loss. As participants ate intuitively, they were convinced they had gained weight, and their accounts suggested that this stemmed from their initial struggles with freedom from dietary restriction. 
"I felt like I was eating less but I didn't necessarily feel like I'd lost weight. I weighed myself and I got a real shock because I had actually lost some weight, and I've been trying to lose that weight for 10 years."

[Extract 18, Participant 9]

"That [eating freely] was difficult at the beginning, and of course when you're making free choices about what you're eating you just assume you're going to be putting weight on. So I didn't stand on the scales because I just thought that would stop me and I'd just want to go on a diet again."

[Extract 19, Participant 4]

To address this in the future, one participant suggested that a form of accountability be developed where participants can check in with someone or are provided with an option to weigh themselves to help alleviate these concerns.

\section{Theme 4: There is empowerment and enjoyment in freedom}

This theme highlights the positive experiences of participants' engagement with freedom. When engaging with the unconditional permission to eat element, participants started to experience empowerment and enjoyment, which was achieved through liberating themselves from dietary restrictions. This theme is presented through two sub-themes.

Subtheme 1: Freedom teaches you to think for yourself

As participants began to understand the ethos of the freedom message, there was a realization amongst all the participants that freedom is "teaching you to think for yourself". Participants developed a sense of empowerment when engaging with this element as they began thinking of their own ways to manage their eating behaviours. Participants were finding out what worked for them and employing strategies they wanted to use rather than obeying dietary rules that had been provided for them by others.

"I think I was taking responsibility for what I was doing, a little bit more than somebody imposing on me."

[Extract 20, Participant 4]

"It [freedom] teaches you how to think for yourself and not to stick to a schedule."

[Extract 21, Participant 1]

\section{Subtheme 2: Freedom diminishes the negative emotions associated with eating}

Throughout the course engaging with the freedom element led participants to feel liberated from negative emotions; there was a realisation that "Food is not the enemy". Participants expressed how the removal of dietary restrictions allowed them to begin to enjoy the foods they previously would have experienced guilt about eating.

"I do eat chocolate still, but I don't crave it, I don't think about it from morning 'til night, which is what I've always done, the whole of my life. It's been almost an obsessive compulsion, so even when I'm dieting successfully I would have that bar of chocolate. I would put it in the cupboard and I would know where it is and I would fixate on it the whole day 'til I was allowed to have it. [Now] days go by when I don't eat chocolate, some days I do, sometimes I eat too much, but it's not [with] that awful guilty [feeling]. I can actually enjoy it whilst I eat it."

[Extract 22, Participant 3] 
Some felt they were in a failing battle, with feelings of failure triggering emotional eating. Dietary freedom helped participants to be released from feeling like a failure.

"I just have whatever I want really. Today I had 2 pieces of toast and honey without too much guilt attached to it, so they weren't horrendous breakfasts but it was really nice to be released from that, because I'm not going through all morning feeling that I've failed already, which is kind of the norm."

[Extract 23, Participant 4]

\section{Theme 5: Addressing more than just a weight problem}

Most of the participants were very much aware of their current weight issues, and the implications these have on their wider health, prior to the programme. However, for most of the participants their weight was not the only issue that required addressing. This theme captures how the programme was an opportunity to address more than just their weight as a quantitative measure. The data for this theme has been captured through the three sub-themes presented below.

\section{Subtheme 1: An opportunity to address other issues}

As previously described, the course delved into a range of issues around a poor relationship with food (e.g., eating in response to emotion, childhood habits), which provided participants with the opportunity to tackle issues that they had not faced before.

"I think things that I've never fully accepted or I've found too difficult and I've just hidden, put to one side, thinking it's all about just losing weight but it's the big thing [about] why I've got myself overweight."

[Extract 24, Participant 5]

"I've found that the week where we were writing letters and kind of really dealing with issues [around] why we have weight gain issues. For me [that] was quite important, it gave me the opportunity to deal with something quite major."

[Extract 25, Participant 3]

Exploring the different issues that can contribute to weight gain gave participants the opportunity to begin understanding their eating behaviours. Some participants had previously identified themselves as emotional eaters. However, following the session around understanding motivations behind eating, they realised they were not emotional eaters but ate in response to feelings of boredom or tiredness. Other participants identified how they had never experienced real physiological hunger and as a result were overeating. In addition, other individuals realised that their issues with food were down to a lack of discipline, which they were now trying to address.

"The biggest thing for me for was the fact that I thought I was an emotional eater, and I'm not. The reason I'm eating isn't, well it is slightly linked to emotion[s] but it's not linked to me being upset or anxious or stressed, which was what was confusing me. I don't feel that my life is controlled by anxiety and stress at the moment; I'm not in a crisis stage at any point. I'm actually going along quite happily. So, my eating is coming from my boredom and maybe slightly loneliness. I'm used to being surrounded by adults and now I'm at home with the kids and that's a different type of thing. My husband works long hours and quite often long days. [So] I eat 'cos I get bored and fed up and it's something that passes the time. The choices of jobs that need doing aren't necessarily things that interest me or I want to do, [so] it actually hasn't got anything to do with being anxious or stressed or emotionally upset, which is good." 


\section{Subtheme 2: Different from previous weight loss attempts}

The importance of having the opportunity to address other issues was further emphasised when participants reflected on their previous weight loss attempts. Participants discussed how previously when they tried to lose weight, their focus would be on reducing the number on the weighing scales. Through this they would experience short-term success, but the real issues they had with food remained unaddressed. Participants' accounts illustrated that beginning to address these issues was in some ways more important than weight loss, which was key to participants' journey through the programme.

"What I've found with all other diets and everything else [is that they've] helped in the short term, but I haven't dealt with the underlying reasons why. I've needed to do that."

[Extract 27, Participant 5]

"I think what's important to me [is that] all the way through my life I've gone to diet clubs or followed a diet or whatever. I haven't ever addressed the mindset that I'm in about food, and how I deal with that, and how I feel about it. You've only got to open my fridge [and] realise it's a healthier fridge. You go to my bedroom there isn't a stash, there's nothing to binge on in my bedroom, which is sort of my secret place. That to me at the moment is almost more important than losing the weight; does that make sense?"

[Extract 28, Participant 8]

As participants continued to reflect on their previous weight loss attempts, they described how exploring these issues and actually beginning to address them was valuable in moving forward and developing a more realistic approach to weight management.

"I've learned things about how I'm eating, and the psychological bit of how I am eating, which in some ways is more important because I can't go through life constantly measuring, weighing, adding up points and all the rest of it. It's got to come from somewhere else and that's gonna take time."

[Extract 29, Participant 10]

\section{Subtheme 3: At times there was too much to take in}

Whilst participants credited the intervention with helping them address these complex issues, it was also evident that at times the content of the course could be too much for participants to take in. As participants progressed through the sessions, they found that the course challenged their existing behaviours, provoking them to form new cognitions and attitudes towards food. Whilst this was considered helpful and necessary, this process was at times described as overwhelming.

“We've already had an awful lot of information. You've learned all this, you know what you've been doing wrong, [and] there's going to be more added to it before you get to the end. I found it piled up a bit, you're uncovering some of your weaknesses, and some of the areas that you're not good at...causing you to reflect on your lifestyle."

[Extract 30, Participant 7]

In addition to this, a few participants suggested that the content of the intervention was overwhelming because the solutions were not given to them. There was an expectation amongst most of the participants that they would be provided with rules to follow, akin to other weight management programmes. The aim of the course was to assist participants with finding their own solutions. Whilst most participants could engage with this, some participants would have preferred solutions from the facilitators. 
"Sometimes I felt perhaps it was a lot without giving us all the answers, but I realise that's not gonna happen, and that shouldn't happen, [it] can't happen, you've got to do it yourself."

[Extract 31, Participant 5]

\section{Theme 6: Coping with other group members}

During each session participants were split into smaller groups of three or four, where they shared their thoughts, feelings and stories. This theme demonstrates how participants felt about this element of the intervention, with participants reporting mixed experiences across their interviews. This has been captured through four sub-themes that are presented below in more detail.

Subtheme 1: The benefits of being in smaller groups

All the participants agreed that separating into small groups of three or four people was a beneficial aspect of the intervention. Being in smaller groups helped to create solidarity, provided a safe environment for discussion and sharing ideas and was a good support system for participants.

"It helps to know that other people go through the same problems [and] the same challenges as you do, and in fact some of them [have] worse challenges."

[Extract 32, Participant 10]

"Yeah I just enjoyed it, it was nice in the discussions to hear how other people were getting on and get other people's input on things, so it was all good."

[Extract 33, Participant 4]

\section{Subtheme 2: People who have bigger issues with eating took over group discussions}

Whilst there were benefits to separating into smaller groups, some participants felt that group members who had bigger or deeper issues associated with eating had the tendency to dominate the group discussion.

“Some people have a lot of ... problems and for me that's not particularly helpful. I'm a very selfish person, it has to be said, not wanting to listen to other people's problems.

\section{[Extract 34, Participant 10]}

When participants found they could not relate to the discussion, they felt they had to hold back from sharing their experiences, which meant their own issues were not always addressed.

"I felt sometimes there were people with much bigger issues, so I [held] back a little bit with my issues. I think maybe it would have been better to be [in] more similar groups, because I think some people with bigger issues took over the discussion and I felt it didn't really speak to me."

[Extract 35, Participant 11]

\section{Subtheme 3: Different opinions about group consistency}

Participants also discussed the consistency of groups and their thoughts on what was most comfortable for them. There were mixed responses on what participants found helpful. For some, keeping groups consistent all the way through was important, as a shared understanding was established and rapport had been built between the group members. By not keeping groups consistent, some participants considered this element was lost. 
“When I came in late, I actually sat with a group [where] I didn't know anybody. I really think it's important that if you're going to do a group that the people that you sit with you kind of develop a rapport with and you understand them because they've talked about their past and their problems with food."

[Extract 36, Participant 12]

As well as keeping groups consistent, some participants also felt that participants should be matched according to the issues they have with food, as this gave further common ground for participants to develop rapport.

"I felt the groups needed to be smaller, better or specifically matched together."

[Extract 37, Participant 13]

However, for other participants mixing groups was better for them. For some this was to prevent cliques developing and for others it was so that they could get different ideas and insights.

"I would have liked to be in different groups ... 'cos otherwise it gets a bit cliquey. You get different ideas off people and where they're coming from and some people are worse than you and you think, 'oh gosh I thought I had problems'."

[Extract 38, Participant 14]

\section{Theme 7: Journeying towards a healthier relationship with food}

This theme captures participants' overall experience of the programme and the next part of their journey. This theme has been captured through three sub-themes.

\section{Sub theme 1: Taste \& See has equipped me with tools}

Participants acknowledged that the programme had not brought around an instant change but rather equipped them with tools to begin developing a better relationship with food. Many of the participants recognised that they were still at the start of their weight loss journey but moving forward in the right direction.

"What it's given me is [an] understanding [of] the dynamics of eating. Why we eat, what are the triggers, what are the internal triggers, and the external triggers and [how] those influences can negatively affect you and how you can make the wrong choices. [The Bible verse] 'Everything is permissible but not everything is beneficial' [has] given me a clearer understanding of how I can stop [and] think before I act, consider it, reflect on things then go do it. It doesn't always work, I'll be honest, it's something you get caught out [with] so it's still breaking those engrained habits and they take time."

[Extract 39, Participant 7]

\section{Subtheme 2: Starting to move forward}

Throughout the course participants learned about their own eating behaviours. At the end of the course, participants identified that they are at the next stage of their journey where they are beginning to use their tools and apply the things they have learned from the intervention.

"I'm trying not to eat between meals but I haven't got to grips ... with this"

[Extract 40, Participant 12]

"[I learned that] there is another way out there and that the way I look at food is not necessarily a healthy way of looking at food. I had my eyes opened to a new way of looking 
at eating and food that I need to grasp and make it become my way of thinking. Does that make sense?"

[Extract 41, Participant 10]

Some participants wanted to repeat the course so they could better consolidate the knowledge they had developed, and make incorporating the intervention into their daily lives easier.

"I really like it and I would love to do it again because I think having got the concept of it, doing it again I'd get a lot more out of it, if that makes any sense? I think it's one of these things you need to do more than once."

[Extract 42, Participant 10]

\section{Sub-theme 3: Final thoughts on the Taste \& See programme}

Overall participants highly commended the programme, meriting the use of spirituality and intuitive eating as approaches towards weight management. The following quotes illustrate participants' final thoughts about the programme.

"I would say I would recommend it to everyone; yeah, I would recommend it to everyone"

[Extract 43, Participant 14]

"I was in a much worse place than I actually really thought I was, and I recognise that I needed to address it [and] I found it hard to address it ... Spirituality and education about healthy eating works."

[Extract 44, Participant 15]

The development of codes into sub-themes and themes is illustrated in Figure 1.

\begin{tabular}{l} 
Codes \\
Not applied faith to food previously \\
Never taken issues with food to God \\
One other problem never taken to God \\
Never prayed about it \\
God isn't interested \\
Eating issues are trivial for God \\
I thought it was too trivial for God \\
Something I should deal with \\
Eating is a failed aspect of life \\
Relationship with God strong \\
Keeping them separate \\
Need to lose weight first \\
\hline God does want to help me
\end{tabular}

Figure 1. Cont. 


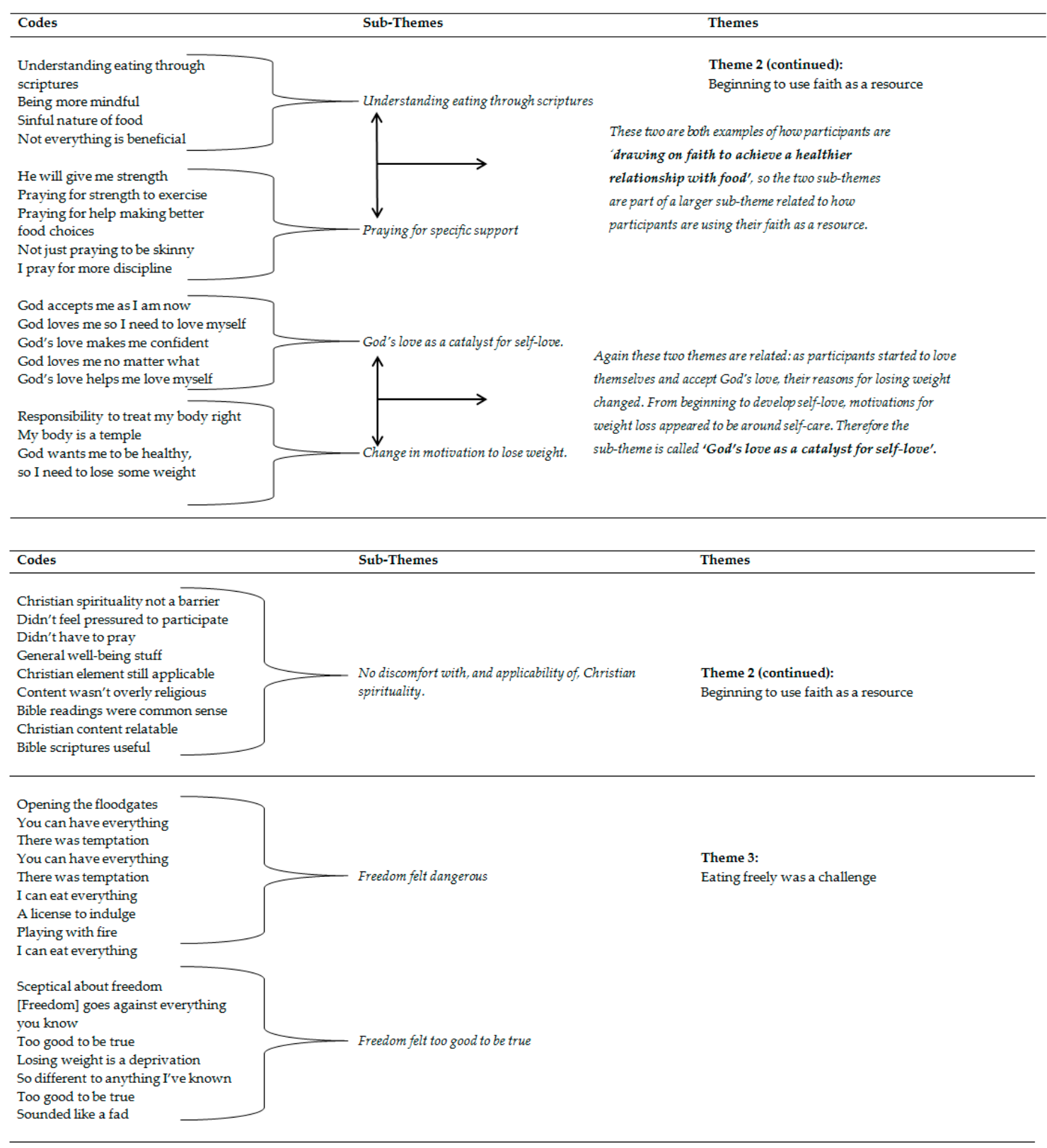

Figure 1. Cont. 


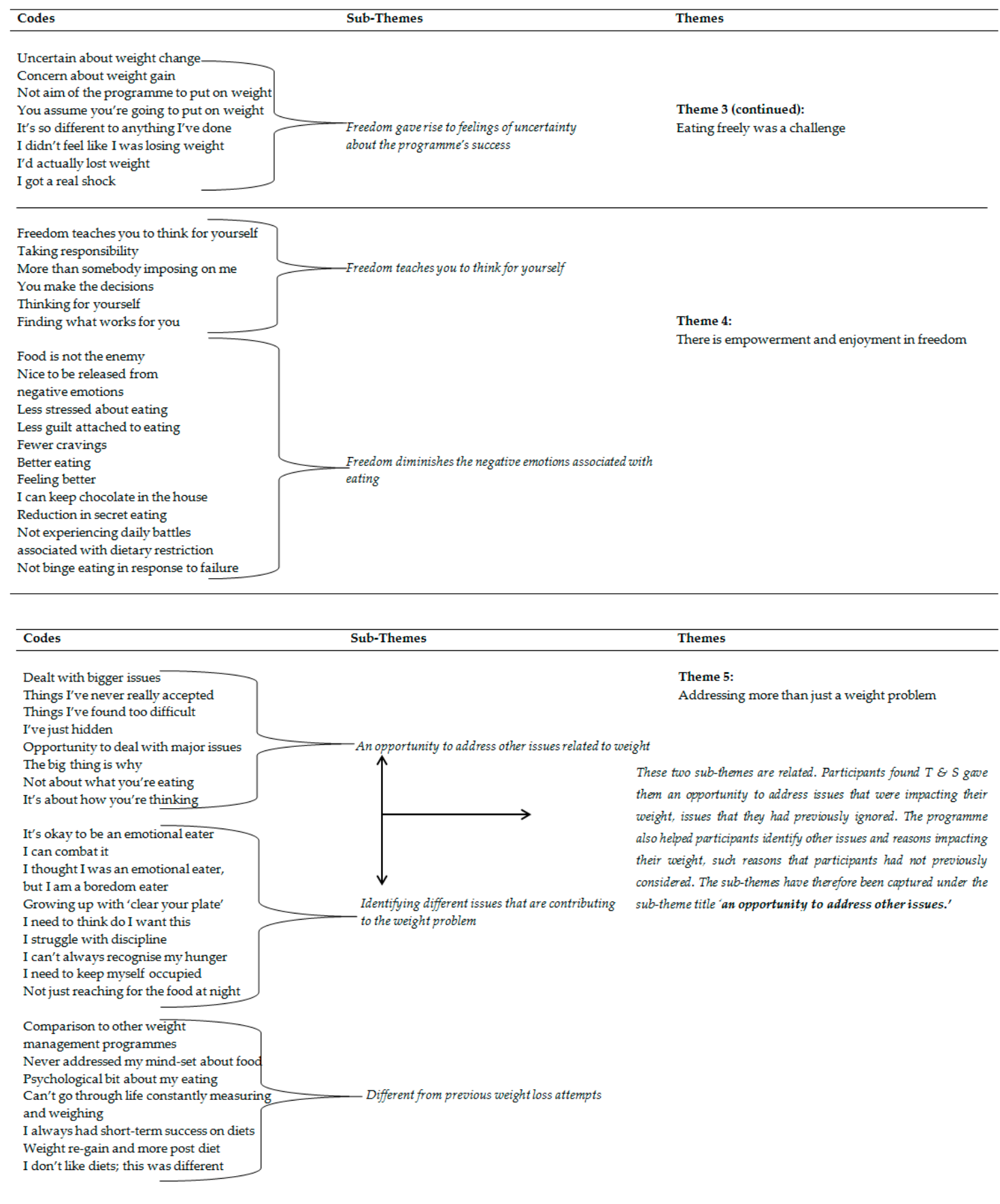

Figure 1. Cont. 


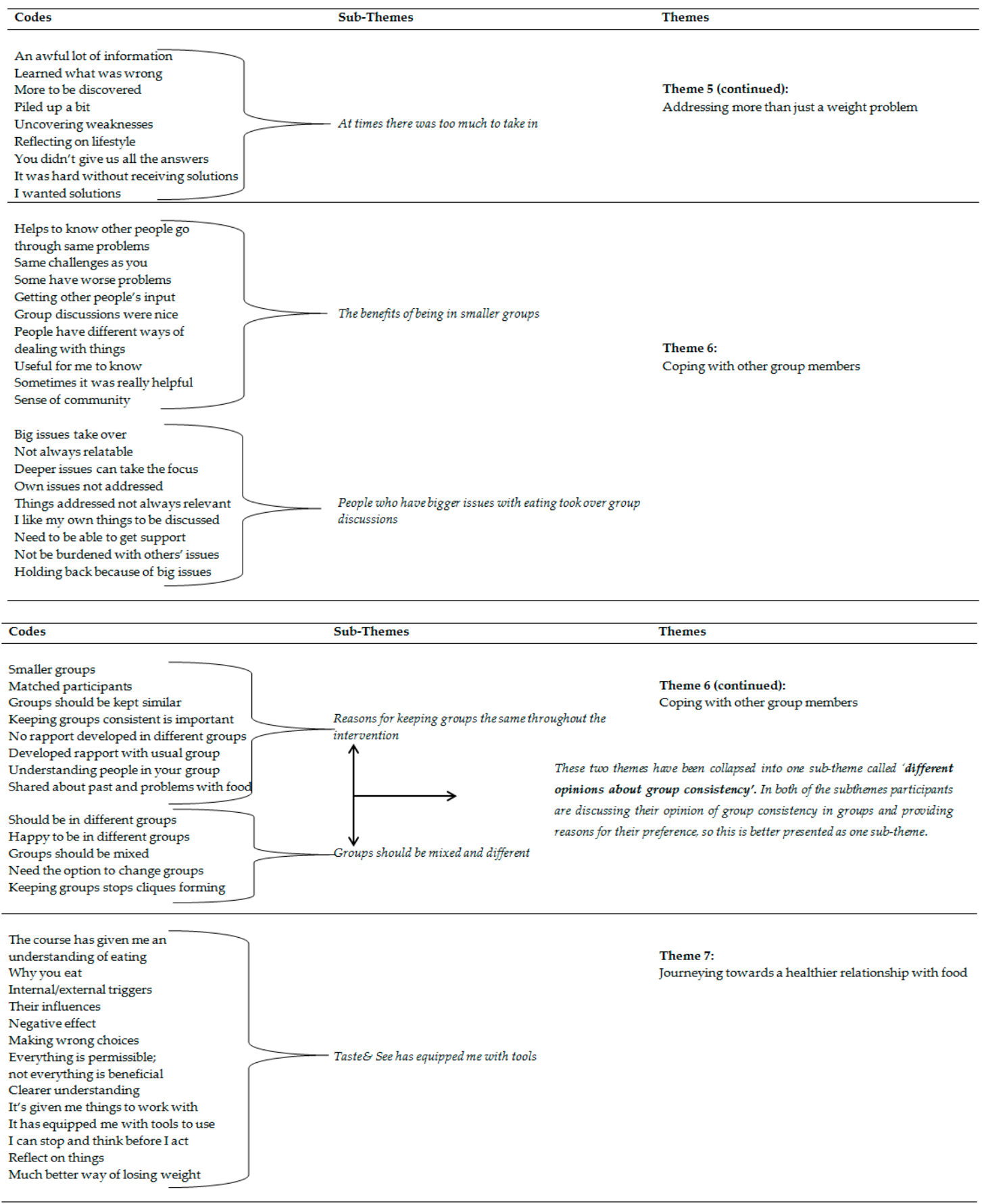

Figure 1. Cont. 


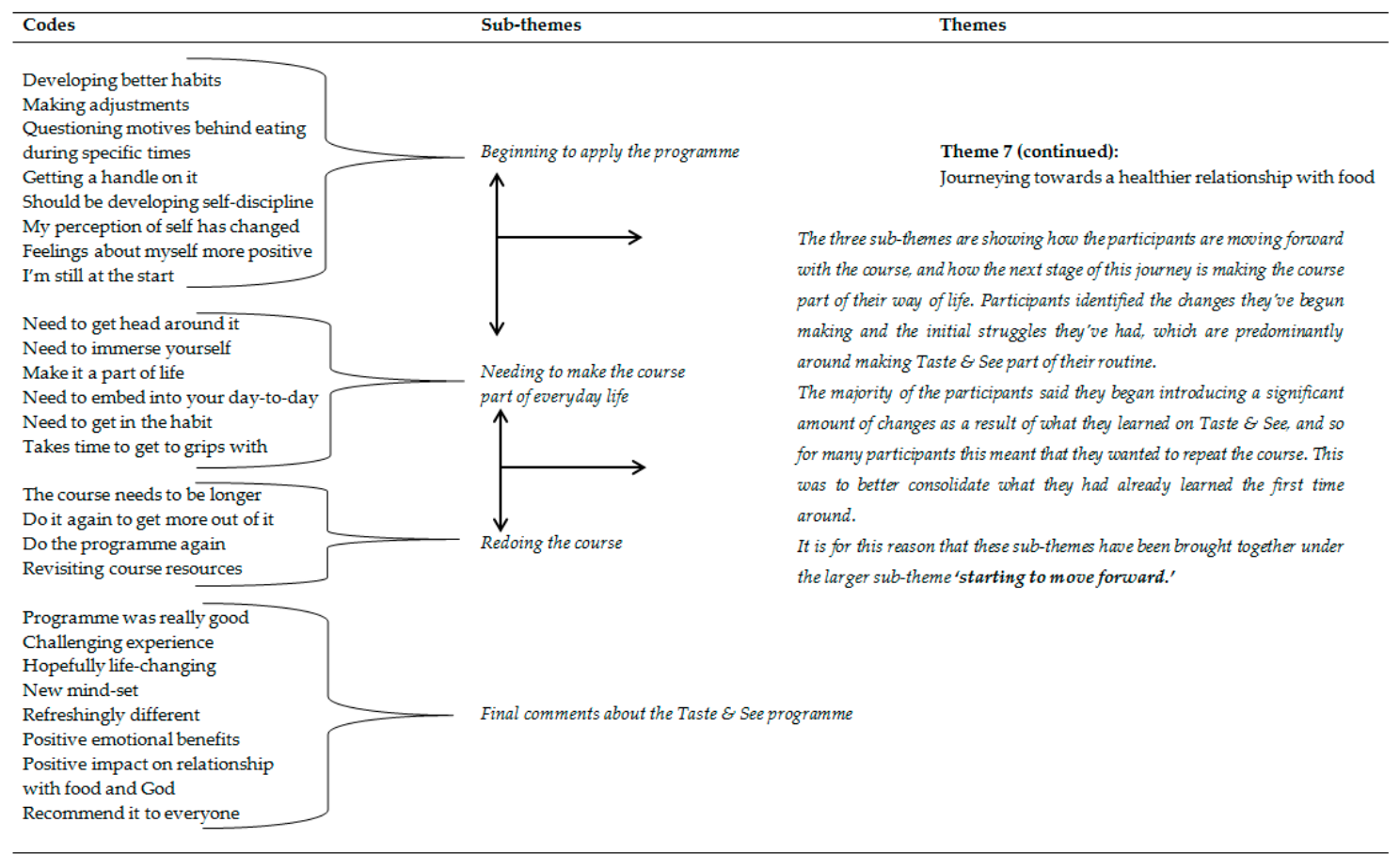

Figure 1. Thematic map of the analysis process displaying how codes were translated into themes.

\section{Discussion}

\subsection{Summary of the Results}

The present study explored how acceptable participants found the Taste \& See intervention, and further explored how they engaged with the different components. The study is part of a feasibility trial; a full report of the trial is reported elsewhere. The Christian weight management programme was a unique and welcome experience for the participants. For most of the participants, the idea of bringing God into their eating was not something they had previously considered despite experiencing considerable struggles with their weight. Participants identified that engaging with the spiritual content of the intervention took them on a journey towards accepting God's help, using their faith as a resource and learning to love themselves the way God loves them. The latter part of the journey formed an important foundation for changing motives to manage their weight post-intervention. Participants found exploring other reasons to eat and how to challenge these behaviours useful, particularly in terms of listening to feelings of hunger and fullness. Similar to their journey with the spiritual element, the freedom element took participants on a journey where early challenges with freedom were related to difficulties in understanding dietary freedom, and fears of weight gain. The freedom element helped participants experience release from the negative emotions associated with food and eating. Participants identified that there were several benefits to being in smaller groups, which included building rapport and developing solidarity through sharing experiences with one another. However, some participants found small group discussions that were dominated by those with deeper emotional issues unhelpful. On the whole, participants felt that the programme helped them take the next step in their journey towards developing a healthier attitude towards food, suggesting acceptance of and engagement with the programme.

\subsection{Strengths and Limitations of the Study}

There are several strengths to the current study. Most of the participants in the feasibility trial took part in the interviews. Our findings have provided unique insights into participants' experiences, which has enabled us to gain a fuller understanding of how this intervention worked and illuminated 
the quantitative findings of our trial. As discussed below, the findings of our study are consistent with previous findings in this area, which increases the credibility of our findings. Furthermore, we reported on the researcher's background, considered the impact this would have on the findings, and took measures to minimize any influence over the results produced. Thematic analysis was used appropriately to answer the research question, and, as described in the methods, through using peer review and keeping an audit trail the rigour of our study was enhanced.

The main limitation of the present study is the small homogenous sample, which limits the transferability of the findings. The participants knew the researchers (Riya Patel and Deborah Lycett) who conducted the interviews; this could have introduced an element of social desirability in the responses participants provided. However, it was emphasized that honest feedback was required from the participants and that this was crucial for the development of the programme.

\subsection{Interpretation of Findings and Consistency with Other Findings}

Previous studies exploring the acceptability of and engagement with interventions of this nature are scarce. The findings of this qualitative study are, however, consistent with the existing literature within this area. Considering the themes around the intuitive eating component, Kidd et al. [16] conducted a one-group pre-test/post-test design mixed methods feasibility study of obese women's lived experience of a mindful eating group intervention. This intervention, although broader in its mindfulness approach, focused on self-regulation theory and encompassed intuitive eating components. The findings of this study echoed the findings of our study, where women in the study highlighted their initial struggles with freedom and being mindful about their eating behaviours. Kidd et al. [16] identified two themes related to mindful eating: 'Feeling the burden, and then the freedom' and 'Bringing control back'. Collectively, these two themes show how participants initially felt burdened by the concept of eating mindfully but, as they began practicing it, they gradually felt more in control of their eating behaviours. Participants' accounts reflect how they became more aware of the social and environmental cues and how these affect their eating. They also reported feelings of increased self-efficacy and positive emotional gains through eating mindfully. This was like the participants in our study, as identified through our themes 'Eating freely was a challenge' and 'There is empowerment and enjoyment in freedom', where there were initial reports of struggle with freedom, but over time participants felt more in control of their eating and experienced increased enjoyment of their food. Kidd et al. [16] also reported findings around the benefits and support of the smaller groups, and how this was a source of encouragement and bonding, which is consistent with the findings of our theme 'coping with other group members'. Kidd et al. [16] also discussed a theme 'Moving from thinking the principles to living the principles'; this particular theme mirrors the findings of our final theme, 'Moving forward in their journey towards a healthier relationship with food', which explored how participants were moving forward with a new way of thinking about eating and taking steps to incorporate what they had learned on the Taste \& See programme into their daily lives. This demonstrates the trustworthiness of our findings.

Our themes around the spiritual element and participants' engagement with this element were similar to those of the participants in Yeary et al. [17]. Yeary et al. [17] described how the connection between participants' faith and health motivated them to change their health behaviours as a sign of devotion to God. Reicks et al. [18] also conducted a qualitative study exploring spirituality in a weight loss programme. Consistent with our findings, Reicks et al. [18] identified how women in the study drew on their relationship with God through praying for help to overcome emotional eating and using Biblical scriptures to understand eating behaviour, which then encouraged women to change their motives for eating. Similarly, the findings of a recent focus group study of participants who had previously participated in a church-based weight loss programme mirrored the findings of our study [19]. Seale et al. [19] concluded that participants anchored themselves on key scriptures, for example 1 Corinthians 6:19, where the body is described as a temple of the Holy Spirit-this provided them with a conscious awareness to treat their bodies better, which in turn motivated 
them to maintain the behavioural changes learned on the interventions. Participants in our study also anchored themselves on specific scriptures including this one when navigating through their daily lives post-intervention. For example, certain scriptures served as prompts for participants to think about their eating behaviour motives, whilst other scriptures encouraged participants to make better choices around food. Furthermore, Seale et al. [19] also found that participants were actively collaborating with God to seek help and find strength beyond their own means to successfully address the struggles they experienced with their weight. This is discussed in our theme 'beginning to use faith as a resource', where participants used the resources available to them through their faith to achieve the lifestyle changes they sought to implement. Collectively, these findings begin to identify what the spiritual component adds to a weight management programme, and how addressing the spiritual needs of the individual during such programmes can be beneficial.

Findings unique to our study were the themes around guilt and shame causing participants to hide their struggles with food and eating from God. When faced with health-related struggles including diagnosis of, or adjustment to, a chronic condition, turning to one's faith and harnessing spiritual beliefs to assist with coping has been observed in the literature [20,21]. It might be that our participants may not perceive obesity as a chronic condition with an immediate health threat, as for example with diabetes or cardiovascular diseases. Furthermore, it could be suggested that these findings are specific to the population under study, as much of the previous research derives from participants of African-American descent, who typically position God centrally in all aspects of their health $[22,23]$ and make the church leader the first port of call for health issues [24,25]; in the United Kingdom, the first port of call for most Christians is the National Health Service. In addition, while the health message about food and diet is central in certain Christian denominations such as Seventh-Day Adventists [26], it is considered much less, and perhaps even not at all, in many other denominations of Christianity. In fact, it has been suggested that overindulgence in food (although not promoted) is overlooked as a 'lesser evil' in comparison to alcohol and smoking [27]. Many religious functions within the church use food, rather than alcohol, as the celebratory good to be consumed [28]. This seems to fit with our findings demonstrated in the subtheme 'drawing on faith to achieve a healthier relationship with food', where food, for some, was not thought about in relation to overindulgence and gluttony prior to completing the Taste \& See programme. Despite this, it is interesting to note that guilt, shame and hiding from God characterised many participants' relationship with food; therefore, it may be that the failure to address these aspects of life spiritually is particularly important in the U.K. population.

\section{Conclusions and Implications}

This is the first study to incorporate intuitive eating and Christian spirituality and the first study to be conducted in a U.K. context. We have shown that participants successfully engaged with a Christian church-based intuitive eating programme. The findings illustrate that the intervention was acceptable to the participants of the study, and support further exploration of interventions of this nature. The rich level of evaluation provided by the participants will be used to improve and enhance the intervention design and evaluation process.

Acknowledgments: We would like to thank the participants who took their time to take part in this study. We gratefully acknowledge the funding of Coventry University. The views expressed here are the opinions of the authors and not of Coventry University.

Author Contributions: D.L. conceived, designed and executed the study, supervised data collection, analysis and the writing of the paper; R.P collected, analysed the data and drafted the paper; A.C. and A.T contributed to the design of the study and drafting of the paper.

Conflicts of Interest: The authors declare no conflict of interest.

\section{References}

1. Frühbeck, Gema, and Volkan Yumuk. "Obesity: A Gateway Disease with a Rising Prevalence." Obesity Facts 7 (2014): 33-36. [CrossRef] [PubMed] 
2. Tan, Min-Min, Carina KY Chan, and Daniel D. Reidpath. "Religiosity, dietary habit, intake of fruit and vegetables, and vegetarian status among Seventh-Day Adventists in West Malaysia." Journal of Behavioral Medicine 39 (2016): 675-686. [CrossRef] [PubMed]

3. Tan, Min-Min, Carina KY Chan, and Daniel D. Reidpath. "Religiosity and spirituality and the intake of fruit, vegetable, and fat: A systematic review." Evidence-Based Complementary and Alternative Medicine 2013 (2013): article 146214. [CrossRef] [PubMed]

4. Obisesan, Thomas, Ivor Livingston, Harld Dean Trulear, and Frank Gillum. "Frequency of attedance at religious services, cardiovascular disease, metabolic risk factors and dietary intake in Americans: An age stratified exploratory analysis." International Journal of Psychiatry in Medicine 36 (2006): 435-48. [CrossRef] [PubMed]

5. Lancaster, Kristie, Lori Carter-Edwards, Stephanie Grilo, Chwan Li Shen, and Antoinette Schoenthaler. "Obesity interventions in African American faith-based organizations: A systematic review." Obesity Reviews 15 (2014): 159-76. [CrossRef] [PubMed]

6. Timmons, Shirley. "Review and evaluation of faith-based weight management interventions that target African American women." Journal of Religion and Health 54 (2015): 798-809. [CrossRef] [PubMed]

7. Craig, Peter, Paul Dieppe, Sally Macintyre, Susan Michie, Irwin Nazareth, and Mark Petticrew. "Developing and Evaluating Complex Interventions: The new Medical Research Council Guidance." BMJ 337 (2008): article a1655. [CrossRef] [PubMed]

8. Lycett, Deborah, Riya Patel, Anne Coufopoulos, and Andy Turner. "Protocol of Taste and See: A Feasibility Study of a Church-Based, Healthy, Intuitive Eating Programme." Religions 7 (2016): article 41. [CrossRef]

9. Patel, Riya, Deborah Lycett, Anne Coufopoulos, and Andy Turner. "A Feasibility Study of Taste \& See: a church-based, programme to develop a healthy relationship with food." under review with Religions.

10. Tong, Allison, Peter Sainsbury, and Jonathan Craig. "Consolidated criteria for reporting qualitative research (COREQ): A 32-item checklist for interviews and focus groups." International Journal for Quality in Health Care 19 (2007): 349-57. [CrossRef] [PubMed]

11. Sobh, Rana, and Chad Perry. "Research design and data analysis in realism research." European Journal of Marketing 40 (2006): 1194-209. [CrossRef]

12. Maxwell, Joseph A. A Realist Approach for Qualitative Research. Thousand Oaks: Sage, 2012.

13. Braun, Virginia, and Victoria Clarke. "Using thematic analysis in psychology." Qualitative Research in Psychology 3 (2006): 77-101. [CrossRef]

14. Kacen, Lea, and Julia Chaitin. "'The Times They are a Changing': Undertaking Qualitative Research in Ambiguous, Conflictual, and Changing Contexts." The Qualitative Report 11 (2006): 209-28.

15. Drake, Pat. "Grasping at methodological understanding: A cautionary tale from insider research." International Journal of Research \& Method in Education 33 (2010): 85-99. [CrossRef]

16. Kidd, Lori I., Christine Heifner Graor, and Carolyn J. Murrock. "A mindful eating group intervention for obese women: A mixed methods feasibility study." Archives of Psychiatric Nursing 27 (2013): 211-18. [CrossRef] [PubMed]

17. Yeary, Karen Hye-cheon Kim, Carol Cornell, Jerome Turner, Page Moore, Zoran Bursac, Elaine Prewitt, and Delia Smith West. "Feasibility of an evidence-based weight loss intervention for a faith-based, rural, African American population." Preventing Chronic Disease 8 (2011): 1-12.

18. Reicks, Marla, Jordan Mills, and Helen Henry. "Qualitative study of spirituality in a weight loss program: Contribution to self-efficacy and locus of control." Journal of Nutrition Education and Behavior 36 (2004): 13-19. [CrossRef]

19. Seale, J. Paul, Judith Fifield, Y. Monique Davis-Smith, Rebecca Satterfield, Joy Goens Thomas, Bonnie Cole, Mark J. Atkinson, and John Mark Boltri. “Developing culturally congruent weight maintenance programs for African American church members." Ethnicity \& Health 18 (2013): 152-67. [CrossRef] [PubMed]

20. Kristeller, Jean L., Virgil Sheets, Tom Johnson, and Betsy Frank. "Understanding religious and spiritual influences on adjustment to cancer: Individual patterns and differences." Journal of Behavioral Medicine 34 (2011): 550-61. [CrossRef] [PubMed]

21. Büssing, Arndt, and Harold G. Koenig. "Spiritual needs of patients with chronic diseases." Religions 1 (2010): 18-27. [CrossRef] 
22. DeHaven, Mark J., Irby B. Hunter, Laura Wilder, James W. Walton, and Jarett Berry. “Health programs in faith-based organizations: Are they effective? " American Journal of Public Health 94 (2004): 1030-36. [CrossRef] [PubMed]

23. Holt, Cheryl L., and Stephanie M. McClure. "Perceptions of the religion-health connection among African American church members." Qualitative Health Research 16 (2006): 268-81. [CrossRef] [PubMed]

24. Levin, Jeffrey S. "Roles for the black pastor in preventive medicine." Pastoral Psychology 35 (1986): 94-103. [CrossRef]

25. Levin, Jeff, Linda M. Chatters, and Robert Joseph Taylor. "Religion, health and medicine in African Americans: Implications for physicians." Journal of the National Medical Association 97 (2005): 237-49. [PubMed]

26. Fraser, Gary E. “Diet as primordial prevention in Seventh-Day Adventists." Preventive Medicine 29 (1999): S18-S23. [CrossRef] [PubMed]

27. Cline, Krista, and Kenneth F. Ferraro. "Does religion increase the prevalence and incidence of obesity in adulthood? " Journal for the Scientific Study of Religion 45 (2006): 269-81. [CrossRef] [PubMed]

28. Sack, Daniel. Whitebread Protestants: Food and Religion in American Culture. New York: Palgrave, 2001.

(C) 2017 by the authors; licensee MDPI, Basel, Switzerland. This article is an open access article distributed under the terms and conditions of the Creative Commons Attribution (CC BY) license (http:/ / creativecommons.org/licenses/by/4.0/). 